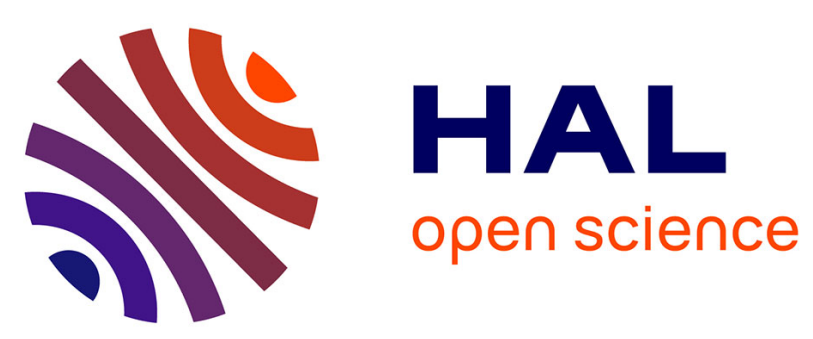

\title{
On the impact of the vertical resolution on chemistry-transport modelling
}

Laurent Menut, Bertrand Bessagnet, Augustin Colette, Dmitry

Khvorostiyanov

\section{- To cite this version:}

Laurent Menut, Bertrand Bessagnet, Augustin Colette, Dmitry Khvorostiyanov. On the impact of the vertical resolution on chemistry-transport modelling. Atmospheric environment, 2013, 67, pp.370-384. 10.1016/j.atmosenv.2012.11.026 . ineris-00961802

\section{HAL Id: ineris-00961802}

\section{https://hal-ineris.archives-ouvertes.fr/ineris-00961802}

Submitted on 20 Mar 2014

HAL is a multi-disciplinary open access archive for the deposit and dissemination of scientific research documents, whether they are published or not. The documents may come from teaching and research institutions in France or abroad, or from public or private research centers.
L'archive ouverte pluridisciplinaire HAL, est destinée au dépôt et à la diffusion de documents scientifiques de niveau recherche, publiés ou non, émanant des établissements d'enseignement et de recherche français ou étrangers, des laboratoires publics ou privés. 


\title{
On the impact of the vertical resolution on chemistry transport modelling
}

\author{
Laurent MENUT ${ }^{1}$, Bertrand BESSAGNET ${ }^{2}$, Augustin COLETTE $^{2}$ and Dmitry KHVOROSTIYANOV ${ }^{1}$ \\ ${ }^{1}$ Institut P.-S. Laplace, Laboratoire de Météorologie Dynamique, CNRS UMR 8539, Ecole Polytechnique, Palaiseau, France. \\ 2 INERIS, Institut National de l'Environnement Industriel et des Risques, Parc technologique ALATA, 60550 Verneuil en Halatte, France
}

\begin{abstract}
This paper presents a sensitivity analysis of the modelling of air pollutant concentrations in the surface layer with the WRF/CHIMERE models. The influence of the vertical resolution near the surface is studied. The simulations are carried out over two periods (winter and summer 2009) over the Paris area. Three model configurations are used: (i) the CHIMERE mesh used for the PREVAIR forecast ( 8 levels from 995 to $500 \mathrm{hPa}$ ), (ii) a mesh refined along the whole vertical axis (20 levels from 995 to $500 \mathrm{hPa}$ ) and (iii) a mesh with a refinement near the surface (9 levels from 999 to $500 \mathrm{hPa})$. The results are discussed in terms of differences on surface concentrations between the reference case and an improved resolution. Adding a point close to the surface appears to be important mainly for high nocturnal concentrations in very stable boundary layers. Refining the vertical mesh, with 20 levels instead of 8 , enables to model new structures in the well mixed boundary layer, but with a moderate impact at the surface. It is shown that the different model configurations lead to changes of a few $\mu \mathrm{g} / \mathrm{m}^{3}$ at most, showing that the vertical mesh is not the most sensitive factor in chemistry-transport modelling when results are compared to surface measurements. This finding validates the fact that a simplified vertical mesh is suitable for air quality forecasting even if an improved vertical resolution close to the ground is important to take into account the urban increment.
\end{abstract}

\section{Introduction}

Albeit the knowledge of pollution sources and meteorology are constantly improved, representing these processes in chemistry transport models (CTM) remains challenging. In particular, the representation of turbulence in the surface layer is difficult and has an important impact on the vertical mixing of meteorological parameters (Cionco and Ellefsen (1998), Kim et al. (2009)) and surface emissions (Pierce et al. (2010)). It influences the whole atmospheric chemical cycle and, in turn, the impact of pollution on human health (Imhof et al. (2005), Andersson et al. (2009), Valari et al. (2011)). In order to improve our knowledge of human exposure, it is necessary to improve the representation of pollutants in the boundary layer and more specifically within the first 100 meters above the ground (Lin and McElroy (2010)). This would give more realistic concentrations values where people live i.e. where the major part of primary pollutants are emitted and where air quality networks monitor pollutant concentrations, while models usually give a "mean vertical concentration value" around 20 to $50 \mathrm{~m}$ above ground level (agl).

The are various techniques used to retrieve more realistic values near the surface in the litterature.

First, a parameterization can be developped to extrapolate $50 \mathrm{~m}$ concentrations (calculated by the CTM) to the surface (Byun and Dennis (1995)). In this case, the extrapolation has to take into account the difference between gaseous and particulate species, because of their chemical and physical characteristics and densities, leading to different settling velocities and deposition rates (Xiao and Taylor (2002), Chamecki et al. (2007)). The challenge consists in building such a parameterization, knowing that pollutant concentrations are exposed to mixing and chemistry (Cheinet and Teixeira (2003)). There is thus no straightforward technique to extrapolate concentrations values down to the ground, because of the nonlinearities in the vertical profile of the concentration near the ground.

A second way would be to embed a Large Eddy Simulation (LES) or a local dispersion model in the CTM (Aristodemou et al. (2009), Garmory et al. (2009), Hara et al. (2009), Lee et al. (2008), Murena et al. (2009), Santos et al. (2009). For example, the ADMS-urban (Righi et al. (2009)) model is sometimes used for urban pollution applications (Davies et al. (2007)). This is certainly the more realistic way in terms of fine turbulence modelling. This method is suitable for complex studies on restricted areas but the methodology is difficult to extend over large domains and not suitable for long term modelling or forecast purposes.

A third technique consists in adding discrete points in the vertical mesh at requested altitudes, or to refine this vertical mesh (Byun and Dennis (1995)). The advantage is that the chemical and meteorological behavior of the surface layer are maintained. This is crucial since most sources are emitted near the surface, such as nitrogen oxides emissions due to traffic in urbanised areas. The main goal of this paper is to estimate the impact of (i) increas- 
ing the number of vertical model levels in the boundary layer, and (ii) changing the first model layer altitude, on pollutant concentrations.

In this study, three model configurations were defined and used to simulate two different periods over the Paris area (January and August 2009). The results are presented in terms of modelled concentrations differences between the configurations and discussed in terms of surface maps and vertical profiles for the usual regulated pollutants: ozone, nitrogen oxides and particulate matter (PM10).

\section{Models configurations}

\subsection{The meteorological model WRF}

The regional model used in this study is the Weather Research and Forcasting (WRF) model in its version 3.2.1. This configuration was already used with CHIMERE for many studies such as Colette et al. (2011) and Menut et al. (2012b), among others. The model is used in its nonhydrostatic configuration. The coarse and fine horizontal domains include $90 \times 70$ and 58x58 grid points, respectively with $45 \mathrm{~km}$ and $15 \mathrm{~km}$ resolutions. The vertical domain covers 38 levels from the surface to $50 \mathrm{hPa}$ and the integration time step is 40 s for the fine domain. For the microphysics, the WRF Single Moment-5 class scheme is used allowing for mixed phase processes and super cooled water, (Hong et al. (2004)). The radiation scheme is RRTMG scheme with the MCICA method of random cloud overlap, (Mlawer et al. (1997)). The surface layer scheme is based on Monin-Obukhov with Carslon-Boland viscous sub-layer. The surface physics is calculated using the Noah Land Surface Model scheme with four soil temperature and moisture layers, (Chen and Dudhia (2001)). The planetary boundary layer physics is processed using the Yonsei University scheme, (Hong et al. (2006)) and the cumulus parameterization uses the Kain-Fritsch scheme for deep and shallow convection using a mass flux approach with downdrafts and CAPE removal time scale (Kain (2004)).

\subsection{The chemistry-transport model CHIMERE}

CHIMERE is an Eulerian off-line chemistry-transport model (CTM), as such it uses prescribed meteorological fields and emissions. The results presented in this paper were obtained with the 2011 a version. Using these meteorological input data and a set of $\mathrm{NO}_{x}, \mathrm{SO}_{x}, \mathrm{NH}_{3}, \mathrm{PM}$, VOCs (Volatile Organic Compounds) and CO emissions, CHIMERE calculates the atmospheric concentrations of tens of gas-phase and aerosol species over local to continental domains (from $1 \mathrm{~km}$ to 1 degree resolution), and with a hourly output time step. All important chemical and physical processes are taken into account: emissions, transport (advection and mixing), chemistry and deposition. The concentrations fields are calculated for pollution event analysis, scenarios studies and forecasts (Menut and Bessagnet (2010)).
The dynamics and gas-phase mechanisms of the model are described in Schmidt et al. (2001), and improvements have successively been carried over (Vautard et al. (2005), Bessagnet et al. (2008)). The model documentation can be found on the web server, (www.lmd.polytechnique.fr/chimere). For both ozone and $\mathrm{PM}_{10}$, the model has undergone extensive modelled aerosols intercomparisons at European and city scales (Vautard et al. (2007); van Loon et al. (2007); Schaap et al. (2007)). The aerosols model species are sulphates, nitrates, ammonium, secondary organic aerosols, primary particles and sea-salt (see Bessagnet et al. (2010) for details). The particle size distribution ranges from about 40 $\mathrm{nm}$ to $10 \mu \mathrm{m}$ distributed in 8 bins. The gas-particle partitioning of the ensemble Sulfate/Nitrate/Ammonium is managed by the ISORROPIA scheme (Nenes et al. (1998)) implemented in CHIMERE.

The surface emissions account for both anthropogenic and biogenic emissions. The biogenic emissions are diagnosed using the MEGAN model (Guenther et al. (2006)). The anthropogenic emissions are based on the EMEP inventory and regridded over the specific CHIMERE domain, by reaggregating the chemical species following the gas-phase and particles chemical mechanism used (Menut et al. (2012a)).

\subsection{Modelling domains}

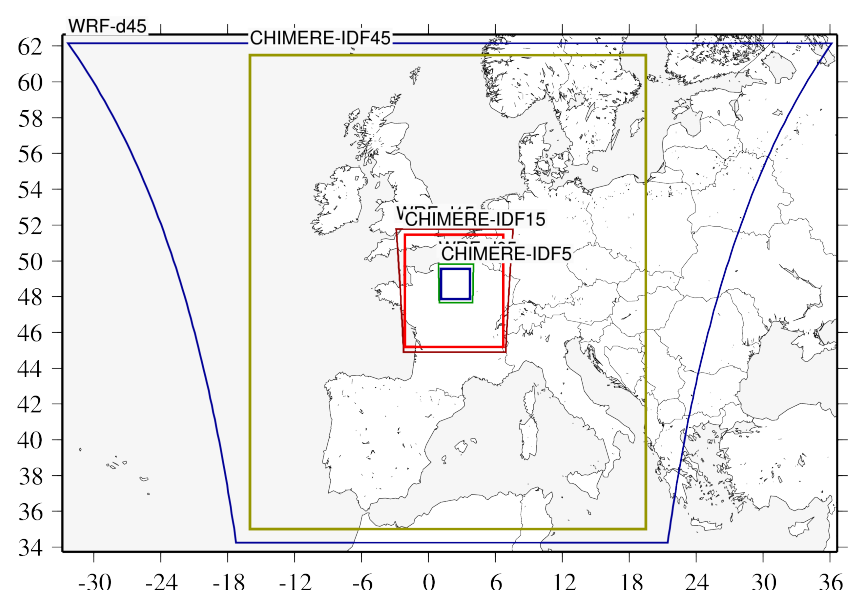

Figure 1: Model simulations domains used for WRF meteorological model and CHIMERE chemistry-transport model.

The simulation domains are centered on the Paris area, as shown in Figure 1. In order to calculate realistic pollutants concentrations, three different domains are nested and are described in Table 1. The largest domain, IDF45, has an horizontal resolution of $0.5^{\circ} \times 0.5^{\circ}$ and covers the whole western Europe. It is designed to describe long-range transport of pollutants and provides accurate boundary conditions to the two other domains. The IDF15 domain has a $15 \mathrm{~km} \times 15 \mathrm{~km}$ horizontal resolution, it is centered over Paris and covers the northern part of France. 
The domain IDF5, has a $5 \mathrm{~km} \times 5 \mathrm{~km}$ horizontal resolution and is located at the center of IDF15. Figure 2 presents the land cover as used by CHIMERE. The city of Paris is considered as $100 \%$ urban. This percentage decreases sharply around the city and the suburb represents a circle around Paris with a radius of $\approx 20 \mathrm{~km}$. For the rest of the domain, the region is mainly composed of agricultural lands, and, to a lesser extent, of grassland and forests.

In this paper, the results of the IDF5 domain are analysed, the IDF45 and IDF15 simulations provide exclusively meteorological and chemical boundary conditions to the IDF5 domain.

\begin{tabular}{lll}
\hline Domain & $\mathrm{Nx} \times \mathrm{Ny}$ & $\Delta \mathrm{x} \times \Delta \mathrm{y}$ \\
\hline IDF45 & & \\
WRF & $72 \times 54$ & $45 \mathrm{~km} \times 45 \mathrm{~km}$ \\
CHIMERE & $68 \times 50$ & $0.5^{\circ} \times 0.5^{\circ}$ \\
\hline IDF15 & & \\
WRF & $49 \times 52$ & $15 \mathrm{~km} \times 15 \mathrm{~km}$ \\
CHIMERE & $45 \times 48$ & $0.2^{\circ} \times 0.133^{\circ}$ \\
\hline IDF5 & & \\
WRF & $46 \times 49$ & $5 \mathrm{~km} \times 5 \mathrm{~km}$ \\
CHIMERE & $38 \times 35$ & $0.07^{\circ} \times 0.05^{\circ}$ \\
\hline
\end{tabular}

Table 1: Model domains set-up as displayed in Figure 1. The WRF model uses a Lambert projection and CHIMERE a Lambert conformal projection

\subsection{Landuse}

There are currently 9 land use categories in CHIMERE. Those categories are calculated from available global land use databases, which can contain different number of classes. In this version, we used the GlobCover Land Cover database, a global land cover map at 10 arc second (300 meter) resolution (Bicheron et al. (2008)). It contains 22 global land cover classes defined within the UN Land Cover Classification System (LCCS). The GlobCover database is based on the ENVISAT satellite mission's MERIS sensor (Medium Resolution Image Spectrometer) Level 1B data retrieved in Full Resolution (FR) mode with a spatial resolution of 300 meters. GlobCover LC was derived from an automatic and regionally-tuned classification of a time series of MERIS FR composites covering the period December 2004-June 2006.

Figure 2 [top] presents the domain landuse in each cell and over the Paris area. Over the whole domain, the 'Agricultural land / crops' is the main landuse type, when the center of the domain is fully urbanised with the Paris city.

\subsection{Vertical meshes}

Three vertical meshes are defined for the sensitivity studies performed with the CHIMERE model. The altitudes of the vertical levels are displayed in Table 2. The three model configurations are described hereafter:

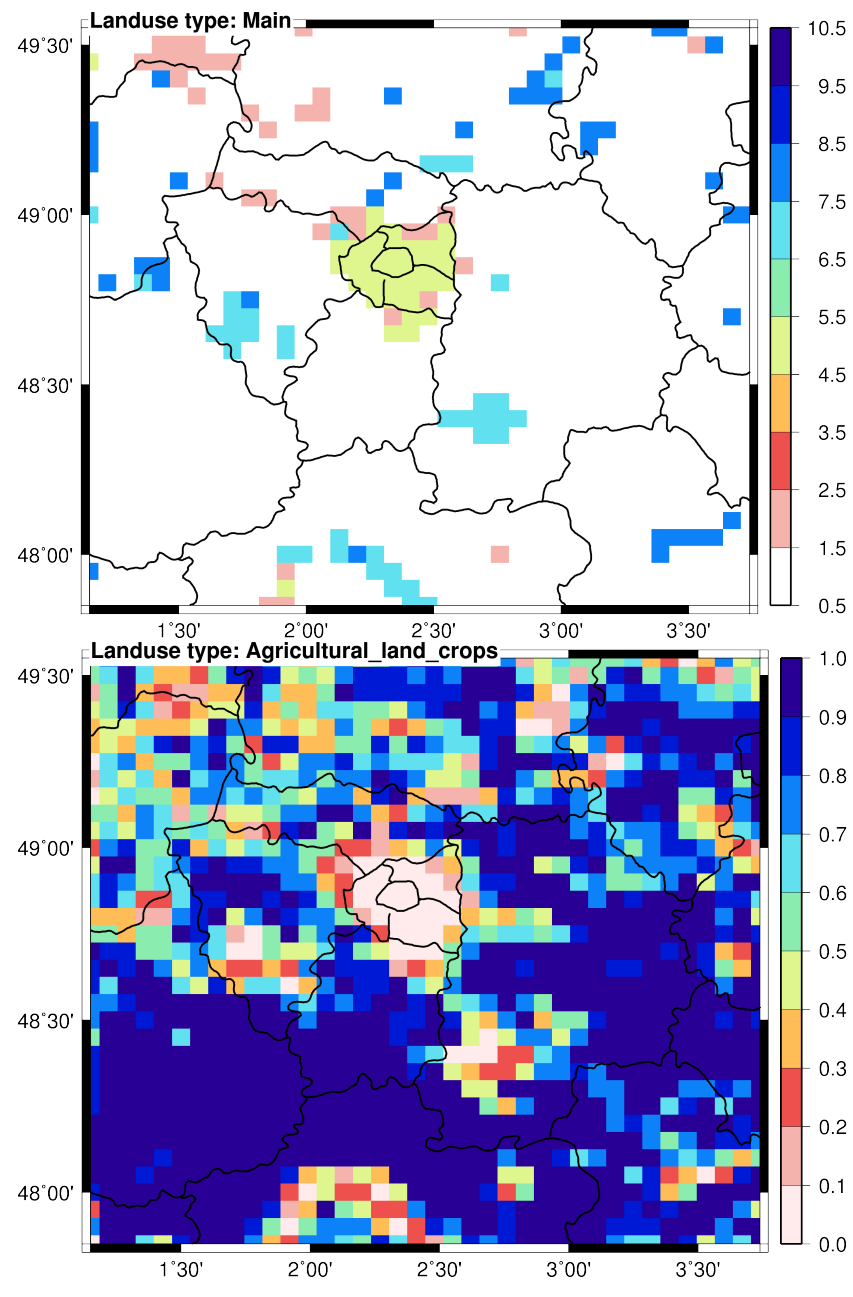

Figure 2: [top] Landuse map for the Paris region: for each cell the dominant landuse is drawed. The color code corresponds to: 1 Agricultural land / crops, 2. grassland, 3. barren land, 4. inland water, 5. urban, 6 shrubs, 7 needleaf forest, 8 broadleaf forest, 9 ocean. [bottom] the relative percentage [0:1] of the first sector, Agricultural land and crops.

- C8: Eight vertical levels are defined from 995 to 500 $\mathrm{hPa}$, representing the lower troposphere, and starting with the first vertical point at about $40 \mathrm{~m}$ above ground level. This corresponds to the operational forecast configuration designed for the PREVAIR system (Rouil et al. (2009)). This configuration is considered in this study as the reference case.

- C20: Twenty vertical levels are defined, also from 995 to $500 \mathrm{hPa}$. This version is designed to examine the impact of a higher resolution mesh compared to C8.

- C9: Nine vertical levels are defined. This is strictly the same as C8 but adding one point near the surface located at $999 \mathrm{hPa}$. This configuration aims at quantifying the variability in the surface concentrations results by adding a point near the surface which would be more representative of measurements. 


\begin{tabular}{ll}
\hline Label & Altitude of levels tops $(\mathrm{m})$ \\
\hline WRF30 & $27 ; 93 ; 153 ; 298 ; 443 ; 627 ; 852 ; 1157 ; 1531 ;$ \\
& $1918 ; 2320 ; 2910 ; 3690 ; 4485 ; 5273 ; 6050 ;$ \\
& $6850 ; 7640 ; 8420 ; 9200 ; 10010 ; 11700 ; 12600 ;$ \\
& $13480 ; 14420 ; 15370 ; 16400 ; 17400 ; 18500 ;$ \\
& 19700 \\
C8 & $40 ; 108 ; 226 ; 431 ; 790 ; 1438 ; 2654 ; 5191$ \\
C9 & $8 ; 40 ; 108 ; 226 ; 431 ; 790 ; 1438 ; 2654 ; 5191$ \\
C20 & $40 ; 86 ; 139 ; 200 ; 271 ; 353 ; 448 ; 559 ; 687 ;$ \\
& $836 ; 1012 ; 1216 ; 1457 ; 1741 ; 2075 ; 2479 ; 2967 ;$ \\
& $3558 ; 4278 ; 5191$ \\
\hline
\end{tabular}

Table 2: Top layers altitudes in meters for the WRF meteorological model (30 levels) and for the three CHIMERE configurations: C8 (8 levels), C9 (9 levels) and C20 (20 levels).

The results will be presented in terms of differences in modelled concentrations fields compared to surface measurements. The following behaviours are expected for the three configurations:

- The C8 and C20 vertical meshes have the same first level point. The only difference is that $\mathrm{C} 20$ has more discrete values in the boundary layer (the number of points in the boundary layer is not constant since it depends on the boundary layer height). By difference between C8 and C20 concentrations fields, the results will quantify the impact of a vertical refinement and thus the impact of the accuracy of meteorological vertical gradients within the boundary layer.

- The C8 and C9 vertical meshes have the same vertical mesh, but C9 has an additional point near the surface. In this case, the mixing and transport within the surface layer would have the same behaviour, but with C9 the model will calculate explicitly a more realistic value at the ground level.

In the next sections, results will be presented either as absolute values for each of the three configurations, or as differences: in that case the $\mathrm{C} 8$ configuration is considered as the reference because it is used in operational forecast mode in the PREVAIR system, Rouil et al. (2009), Honoré et al. (2008), Menut and Bessagnet (2010).

\subsection{Estimation of turbulent parameters}

CHIMERE offers the possibility to use either diagnostic available variables from meteorological drivers or diagnose some meteorological variables in the pre-processing step. In this study, the latter option is selected in order to use the same turbulent parameterizations and also to be consistent with the CHIMERE model configuration used in the PREVAIR system (Rouil et al. (2009)). The full WRF vertical resolution is used to diagnose the vertical turbulent diffusivity $\mathrm{K}_{z}$ and the boundary layer height $\bar{h}$. After this evaluation, the diagnosed profiles of $K_{z}$ are averaged over the CHIMERE vertical grid in the same way as all others meteorological parameters. It is during this final vertical averaging that the number of vertical levels used by the CHIMERE model are changed.

The following variables are calculated: the friction velocity $\mathrm{u}_{*}$, the surface sensible heat flux $\mathrm{Q}_{0}$, the vertical convective velocity $\mathrm{w}_{*}$, the boundary layer height $\bar{h}$, the Monin-Obukhov length $L$ and the vertical diffusivity profile $\mathrm{K}_{z}$.

The friction velocity $\mathrm{u}_{*}$ is used for deposition and the calculation of diffusivities. It is a particularly sensitive parameter for ozone in summer through the calculation of aerodynamic resistance $\mathrm{r}_{a}$. It depends strongly on land use types which are critical to deposition. In large scale meteorological models, roughness lengths are sometimes too coarse and cannot be applied for high-resolution deposition. Recomputing $\mathrm{u}_{*}$ as proposed by Louis et al. (1982) gives satisfactory results. In addition it yields a deposition that is consistent with the high-resolution land use.

$$
u_{*}=\sqrt{C_{D N}^{2} F_{m}|u(z)|^{2}}
$$

where $F_{m}$ is the Louis et al. (1982) stability function, $z$ the height above ground level where the meteorological data are available (in our case $z=10 \mathrm{~m}$ ). $C_{D N}$ the neutral drag coefficient as:

$$
C_{D N}=\frac{k}{\ln \left(\frac{z+z_{0 m}}{z_{0 m}}\right)}
$$

with $k=0.41$, the Karman constant. $z_{0 m}$ is the dynamical roughness length (in meters) and values are tabulated for each landuse type. $F_{m}$ is the momentum stability function and is estimated depending on the bulk Richardson number value. Under stable cases (if $R_{i b}<0$ ):

$$
F_{m}=1-\frac{2 b R_{i b}}{1+3 b c C_{D N}^{2} \cdot \sqrt{\frac{z+z_{0 m}}{z_{0 m}}} \sqrt{\left|R_{i b}\right|}}
$$

and under unstable cases (if $R_{i b}>0$ ):

$$
F_{m}=\frac{1}{1+\frac{2 b R_{i b}}{\sqrt{1+d R_{i b}}}}
$$

with the constant $b=c=d=5$. Under neutral case, i.e $R_{i b}=0, F_{m}=1$.

The bulk Richardson number is estimated as:

$$
R_{i b}(z)=\frac{g z}{\overline{\theta_{v}(z)}} \frac{\Delta \overline{\theta_{v}}}{\Delta|U|^{2}}
$$

with $\Delta \overline{\theta_{v}}=\overline{\theta_{v}}(z)-\overline{\theta_{v}}\left(z_{0}\right), \Delta|U|=|U|(z)$.

Heat fluxes are used for the calculation of $\mathrm{w}_{*}$ (and therefore the vertical mixing), and the height of the boundary layer. Only the virtual heat flux is required, which can be recalculated from an empirical formula Priestley (1949) using temperatures in the first meteorological model layers. Because of uncertainties in the later formula, it is strongly 
advised to use the heat fluxes of the meteorological model if available. If the surface sensible heat fluxes $Q_{0}$ are provided by the meteorological model, they are directly used for the calculation of the convective velocity $\mathrm{w}_{*}$ :

$$
w_{*}=\left(\frac{g Q_{0} \bar{h}}{\rho C_{p} \overline{\theta_{v}}}\right)^{1 / 3}
$$

where $g=9.81 \mathrm{~m}^{2} . \mathrm{s}^{-2}, Q_{0}$ is the surface sensible heat flux, $\bar{h}$ is the convective boundary layer height, $C_{p}$ is the specific heat of air at constant pressure, $\overline{\theta_{v}}$ is the mean virtual potential temperature representative of the surface layer.

The Monin-Obhukov length is estimated as:

$$
L=\frac{-\overline{\theta_{v}} u_{*}^{3}}{k g Q_{0}}
$$

The boundary layer height $(\bar{h})$ differs for stable and unstable conditions. Under stable conditions, i.e when $L>0$, $\bar{h}$ is estimated as the altitude where the Richardson number reaches a critial number here chosen as $R_{i c}=0.5$, following Troen and Mahrt (1986).

Under unstable (i.e convective) conditions, $\bar{h}$ is also chosen as the altitude where $R_{i}=R_{i c}$, including the influence of boundary layer convective clouds. The latter is based on a simplified and diagnostic version of the approach of Cheinet and Teixeira (2003). It consists in the resolution of the (dry) thermal plume equation with diffusion. The in-plume vertical velocity and buoyancy equations are solved and the boundary layer is taken as the height where the vertical velocity stops. Thermals are initiated with a non-vanishing vertical velocity and potential temperature departure, depending on the turbulence similarity parameters in the surface layer.

A usual approximation for CTMs, considered as numerically diffusive, is to neglect the horizontal turbulent fluxes. Vertical turbulent mixing takes place only in the boundary-layer. The formulation uses K-diffusion following the parameterization of Troen and Mahrt (1986), with no counter-gradient term. In each model column, the diffusivity $\mathrm{K}_{z}\left(\mathrm{~m}^{2} / \mathrm{s}\right)$ is calculated as:

$$
K_{z}=k w_{s} \frac{z}{\bar{h}}\left(1-\frac{z}{\bar{h}}\right)^{2}
$$

In this equation, $w_{s}$ is a vertical scale given by similar formulas:

- In the stable case (when the surface sensible heat flux is negative):

$$
w_{s}=\frac{u_{*}}{(1+4.7 z / L)}
$$

- In the unstable case:

$$
w_{s}=\left(u_{*}^{3}+2.8 e w_{*}^{3}\right)^{1 / 3}
$$

where $e=\max (0.1, z / \bar{h})$. A minimal $\mathrm{K}(\mathrm{z})$ is assumed, with a value of $0.01 \mathrm{~m}^{2} / \mathrm{s}$ in the dry boundary layer and of $1 \mathrm{~m}^{2} / \mathrm{s}$ in the cloudy boundary layer. In the boundary layer, a maximal value of $\mathrm{K}_{z}=500 \mathrm{~m}^{2} / \mathrm{s}$ is used to avoid unrealistic mixing. Above the boundary layer, a fixed value of $\mathrm{K}_{z}=0.1 \mathrm{~m}^{2} / \mathrm{s}$ is prescribed.

\section{Overview of the two periods}

\subsection{Meteorological conditions}
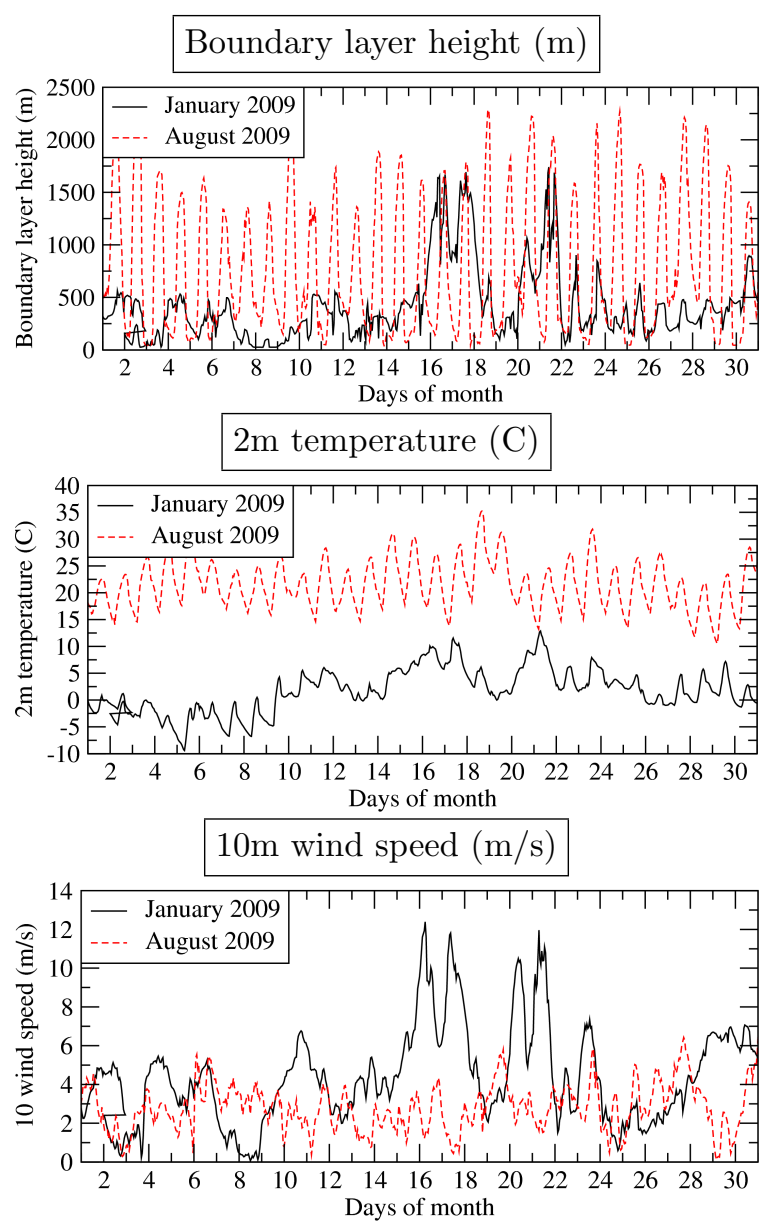

Figure 3: Times series of the mean meteorological parameters for the period of January and August 2009 at the center of the domain: Paris.

The results in this study are presented for the 1-31 January and 1-31 August 2009 periods. These periods consist of one winter and one summer month over the Paris area, in order to cover several meteorological situations leading to pollution events in this region. These periods were selected for the following reasons: (i) they correspond to "classical" meteorological situations leading to normal pollution episodes; (ii) no precipitations were recorded, leading to a more robust analysis of the modelled vertical mixing of pollutants, (iii) in the two cases, pollution events were reported by the local air quality networks. 
Time series of meteorological parameters such as $2 \mathrm{~m}$ temperature, boundary layer height and $10 \mathrm{~m}$ wind speed are presented in Figure 3 . These parameters correspond to the meteorological parameters used by the CHIMERE model. They are fully independent from the vertical resolution chosen for the chemistry-transport modelling. The boundary layer heights are very different between January and August: the diurnal cycle is rather low during January when values quickly evolve during the daytime in August. In January, the mean values are $\approx 400 \mathrm{~m}$, and maximal values of $\approx 1500 \mathrm{~m}$ are observed between the 15 and 22 January. In August, the boundary layer top is always between 1500 and $2500 \mathrm{~m}$. The $2 \mathrm{~m}$ temperature also exhibits low diurnal cycles during January and a high daily amplitude in August. The mean values are $\approx 0$ and $23^{\circ} \mathrm{C}$ for January and August, respectively. In summer, the nocturnal values are relatively low (from 10 to $15^{\circ} \mathrm{C}$ ). The $10 \mathrm{~m}$ wind speed is low in August, with a mean value of $\approx 3 \mathrm{~m} / \mathrm{s}$ favourable to stagnation and, thus, photochemical pollution episodes. During winter, the $10 \mathrm{~m}$ wind speed may rapidly change, from very low wind periods (e.g. 8 January) to high surface wind speed days (e.g. 16, 18, 22 January). These high wind speed values of mid-January explain the high boundary layer height diagnosed for that period.

\subsection{Pollutant concentrations}

The first model level concentrations maps are displayed in Figure 4 for $\mathrm{NO}_{2}, \mathrm{PM}_{10}$ and $\mathrm{O}_{3}$ (in $\left.\mu \mathrm{g} / \mathrm{m}^{3}\right)$. The model configuration considered as the reference case is the C8 simulation (Honoré et al. (2008)). The maps represent monthly average concentrations over January and August 2009. Even if absolute values are different between summer and winter, the regional patterns are similar for the three pollutants $\mathrm{O}_{3}, \mathrm{NO}_{2}$ and $\mathrm{PM}_{10}$. The Paris area is at the center of the domain and exhibits the major source of primay pollutants such as $\mathrm{PM}_{10}$ and $\mathrm{NO}_{2}$. The limited spread around the city correspond to the mean concentrations transported a few kilometers out of the city center, and each pattern represents the mean wind direction during each month.

For both periods, the maximum values of $\mathrm{NO}_{2}$ and $\mathrm{PM}_{10}$ are observed over Paris, characterised by the most important anthropogenic emissions fluxes. Due to fast chemical reactions (mainly titration), Paris is also the location of the lowest surface ozone values: $\approx 20 \mu \mathrm{g} / \mathrm{m}^{3}$ in January and $\approx 70 \mu \mathrm{g} / \mathrm{m}^{3}$ in August.

Around Paris, background values are homogeneous and lower, averaging the potential ozone plumes and the background concentrations (local biogenic production or longrange transport, Menut et al. (2000), Derognat et al. (2003)). The main differences are observed for ozone, the background averaged values are $\approx 40-50 \mu \mathrm{g} / \mathrm{m}^{3}$ in winter and $\approx 70-80 \mu \mathrm{g} / \mathrm{m}^{3}$ in summer.

\section{Impact of a higher vertical resolution}

\subsection{Monthly averaged surface concentrations}

The comparisons are presented for the differences (C20$\mathrm{C} 8$ ) and (C9-C8), for the three studied pollutants, $\mathrm{O}_{3}$, $\mathrm{NO}_{2}$ and $\mathrm{PM}_{10}$, and for January and August 2009. Results are displayed in Figure 5 and for the first vertical level only: it represents the "surface" concentrations i.e the mean value between the ground and the top layer altitude. Such concentrations are the values usually compared to the air quality measurements stations. For (C20-C8), the model configurations have the same first vertical level but not the same vertical resolution. A direct comparison between the first model level horizontal fields gives the direct impact of an increased vertical resolution. For (C9$\mathrm{C} 8$ ), the first vertical levels are not at the same altitude above ground level: 8 and $40 \mathrm{~m}$ respectively. It shows the potential improvement of adding a lower first level close to the observations (i.e usually $\approx 3 \mathrm{~m}$ ).

Globally, the maps represent surface concentrations and not surface emissions. The most important emissions are located in the Paris city center (the center of the modelled domain). Due to horizontal transport and chemistry, the main differences are observed (i) in the south-west of Paris during January and August 2009 , due the meteorology during this period. Thus, the most important impact appears to be in the suburb but has to be directly rely to the changes in the Paris city center.

For $\mathrm{NO}_{2}$ surface concentrations (Figure 5, left), the differences are very low and never exceed $\pm 3 \mu \mathrm{g} / \mathrm{m}^{3}$. In January, the main negative differences (i.e. C8 $>$ C20) are observed in the center of the Paris area, while the main differences of positive sign are observed at the border of the domain. For the same period, the contrary is observed for (C9-C8), more logically directly linked to the fact that the compared vertical levels are different and that the $\mathrm{NO}_{2}$ concentrations are always more important near the surface due to traffic emissions. In August, the (C20-C8) values are close to zero due to the photochemistry for the same vertical level and close to the ground. But some non negligible values may be observed with (C9-C8), with higher values for $\mathrm{C}$, for the same reason than during January.

For $\mathrm{PM}_{10}$ surface concentrations, the differences are larger and C20 shows concentrations higher by +0.5 to $+2 \mu \mathrm{g} / \mathrm{m}^{3}$ all over the domain in August and January, respectively. The differences are spatially more homogeneous over the domain for $\mathrm{PM}_{10}$ than for $\mathrm{NO}_{2}$. The main components of $\mathrm{PM}_{10}$ are a primary anthropogenic fraction and a secondary biogenic origin.

For $\mathrm{O}_{3}$ concentrations, the differences are always negative, so that $\mathrm{C} 8>\mathrm{C} 20$ over the whole domain. For January and August, the differences range is -3 to $-1 \mu \mathrm{g} / \mathrm{m}^{3}$. The differences are not spatially homogeneous and have to be directly related to the spatial patterns observed for $\mathrm{NO}_{2}$ over the main source of the Paris city. The $\mathrm{O}_{3}$ deposition in the C9 simulations is enhanced over forested 


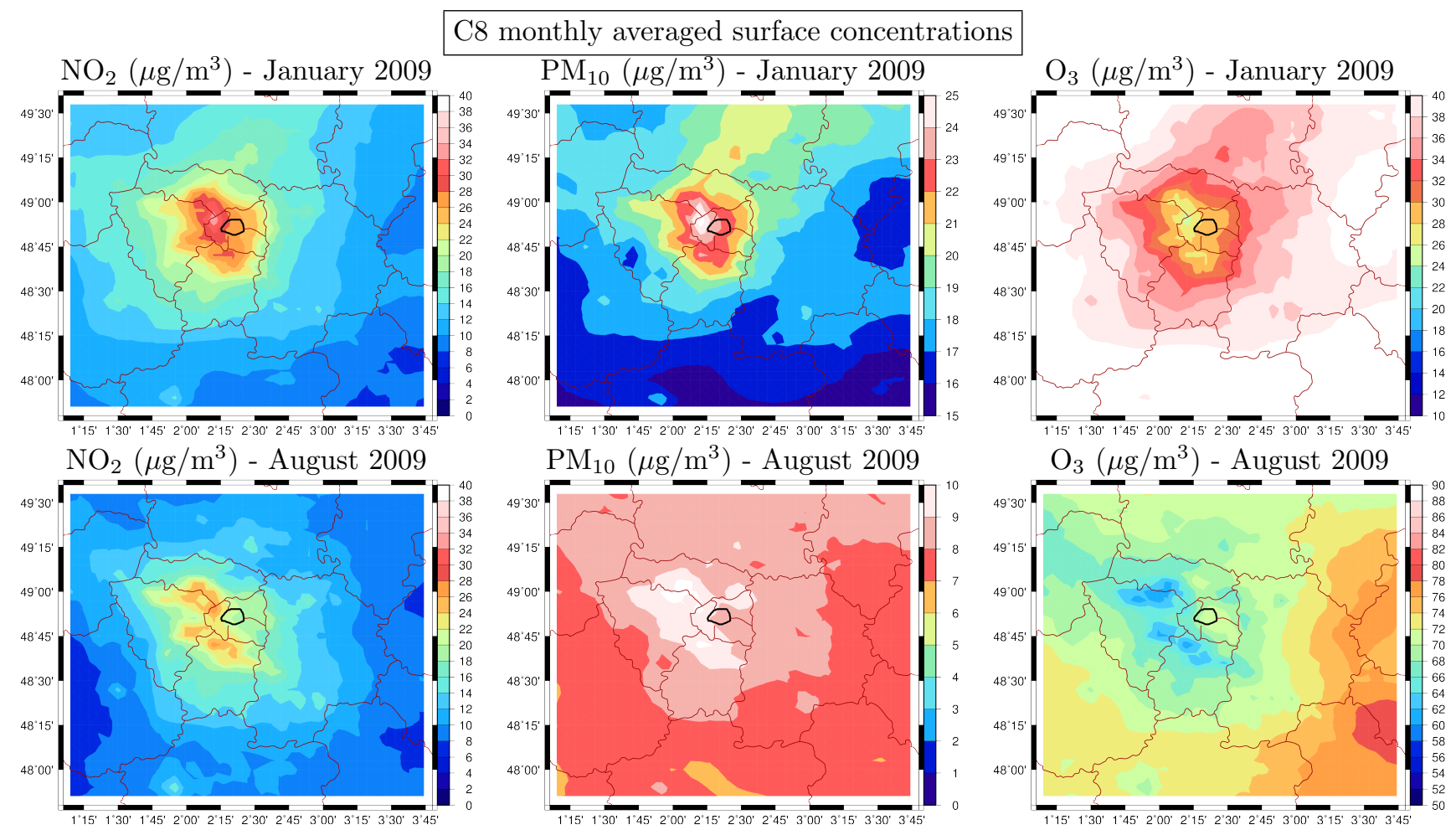

Figure 4: Maps of monthly mean averaged surface concentrations for $\mathrm{NO}_{2}, \mathrm{PM}_{10}$ and $\mathrm{O}_{3}$, and for the months of January and August 2009.

areas, lower concentrations are simulated compare to the reference simulation $\mathrm{C} 8$.

For the three pollutants, the differences reach on average $\pm 3 \mu \mathrm{g} / \mathrm{m}^{3}$. For $\mathrm{PM}_{10}$ and $\mathrm{O}_{3}$, Figure 5 clearly shows that refining the whole vertical mesh has a large scale impact, while adding one level near the surface has a more variable impact at the local scale depending on emissions and landuses.

\subsection{Vertical cross sections}

In this section, the analysis focussed on the vertical structure. Vertical time series are displayed to estimate the impact of the different vertical meshes on the whole troposphere concentrations. Two examples are chosen: the vertical profiles of $\mathrm{PM}_{10}$ during winter (January 2009, Figure 6 , left panel) and ozone during summer (August 2009, Figure 6, right panel). As for all following results, the modelled concentrations are extracted from the model cell the most affected by the anthropogenic emissions, the Paris city center (longitude $2.35^{\circ} \mathrm{W}$ and latitude $48.86^{\circ} \mathrm{N}$ ).

The comparison is purposely limited to a qualitative discussion. Since the vertical resolution is different, a quantification would require to interpolate the pollutant concentrations at identical altitudes. This interpolation process at such low native resolution would generate more differences than the differences observed between the three models configurations. Therefore, the results are thus just qualitatively discussed in this section.
The vertical $\mathrm{PM}_{10}$ profiles showed that the largest concentrations are simulated close to the surface, due to anthropogenic emissions. During the month of January 2009, the most important concentrations are observed during the first two and the last weeks. The lowest concentrations are observed during the period of 14 to 22 January 2009, being those when the highest boundary layer height and $10 \mathrm{~m}$ wind speed values are modelled ( Figure 3 ): surface concentrations are vertically mixed and/or advected out of the modelled domain. The impact of C20 appears clearly around the 20th of January, when a concentration of $\approx 20$ $\mu \mathrm{g} / \mathrm{m}^{3}$ is modelled between 800 and $1000 \mathrm{~m}$, but not with $\mathrm{C} 8$ and $\mathrm{C} 9$. The same type of structure, only modelled by C20, is also observed on January, 27 between 900 and $1000 \mathrm{~m}$.

The vertical profiles of ozone are different, ozone has always larger concentrations in the upper boundary layer than near the surface, when fast titration by $\mathrm{NO}_{x}$ occurs. The C20 configuration shows that the vertical gradients are more pronounced than for $\mathrm{C} 8$ and $\mathrm{C} 9$, mainly around $3000 \mathrm{~m}$, at the top of the boundary layer. But, on average, the most important vertical structures are modelled and the number of vertical levels does not seem to impact much the behaviour of ozone in the boundary layer. The most important differences are observed up to $4000 \mathrm{~m}$, showing that a finer resolution has an impact on the representation of long-range transport.

The comparison of vertical profiles for the three configurations showed that $\mathrm{C} 20$ is able to model ozone and 
$\mathrm{PM}_{10}$ in the boundary layer with differences up to 10 to $20 \mu \mathrm{g} / \mathrm{m}^{3}$. These differences are often above the boundary layer and are related to long-range transport rather than local production. This feature shows that the vertical refinement has a moderate impact on surface concentrations.

\subsection{Analysis of monthly mean vertical profiles}

In order to better evaluate the impact of the vertical resolution on concentrations profiles, the concentrations displayed in Figure 6 are averaged on a monthly basis and presented for each model configuration in Figure 7 . The upper panel presents $\mathrm{K}_{z}$ vertical profiles for two hours, 06:00 UTC and 15:00 UTC. For 06:00 UTC, for example, this means that all profiles of January and August at 06:00 UTC are averaged to obtain one profile for each month, representative of this specific hour. For $\mathrm{O}_{3}$ and $\mathrm{NO}_{2}$ pollutants, all hourly profiles of the month are averaged.

The $\mathrm{K}_{z}$ profiles show different shapes and magnitudes between 06:00 and 15:00 UTC. At 06:00 UTC, before the convective period, the values of diffusivity are low and do not exceed 30 and $70 \mathrm{~m}^{2} / \mathrm{s}$, at $\approx 300 \mathrm{~m}$ and $1000 \mathrm{~m}$, in January and August, respectively. The shape of the profile is noisy because of the day to day variability. Note that the standard deviation was not found as a relevant information here, its values being of the same order of magnitude as the mean profiles. The $\mathrm{K}_{z}$ values are more important during summer than the winter, and may reach up to $160 \mathrm{~m}^{2} / \mathrm{s}$ in August at 15:00 UTC, for a mean altitude of $1000 \mathrm{~m}$. For all times and periods, the most important differences are in the lowest layer in the C9 simulation, showing that the extra point close to the surface generates a very low mixing $\left(\mathrm{K}_{z}<2 \mathrm{~m}^{2} / \mathrm{s}\right)$, whilst the two other simulations always display minimum values between 5 and $10 \mathrm{~m}^{2} / \mathrm{s}$.

The $\mathrm{NO}_{2}$ profiles show maximum values close to the surface, where emissions take place. The differences between C8 and C20 are rather low, as previously showed with the horizontal maps in Figure 5 . The differences between C9 and the two other configurations are important, the concentrations gradually increase close to the ground. This leads to an increase of $\mathrm{NO}_{2}$ concentrations of $\approx 1 \mu \mathrm{g} / \mathrm{m}^{3}$ in January and $\approx 3 \mu \mathrm{g} / \mathrm{m}^{3}$ August 2009 .

For ozone, concentrations usually increase with altitude. This leads to lower values near the surface with C9. The differences are very low and never exceed a few $\mu \mathrm{g} / \mathrm{m}^{3}$ compared to $\mathrm{C} 8$ and $\mathrm{C} 20$. Up to $40 \mathrm{~m}$, the $\mathrm{C} 8$ and $\mathrm{C} 9$ profiles are similar and show large differences comparted to the $\mathrm{C} 20$ profile. The $\mathrm{C} 20$ concentrations are lower between $40 \mathrm{~m}$ and $1500 \mathrm{~m}$, but higher up to $1500 \mathrm{~m}$. The same impact is observed on the January profile, but with an inversion of differences around $700 \mathrm{~m}$. This feature reflects the impact of a refined vertical transport, between the boundary layer and the free troposphere.

The monthly mean concentrations profiles showed that the C8 and C9 configurations have the same values down to $40 \mathrm{~m}$. The additional point with $\mathrm{C} 9$, around $8 \mathrm{~m}$ above groud level, appears as an extrapolation of the upper profile. This leads to higher primary pollutants (here $\mathrm{NO}_{2}$ ) and lower ozone concentrations at the first model vertical level. However, differences remain low and an additional extrapolation to 1 or $2 \mathrm{~m}$ above ground level would not give large variations in surface time series of pollutants.

\subsection{Sensitivity to the vertical mixing}
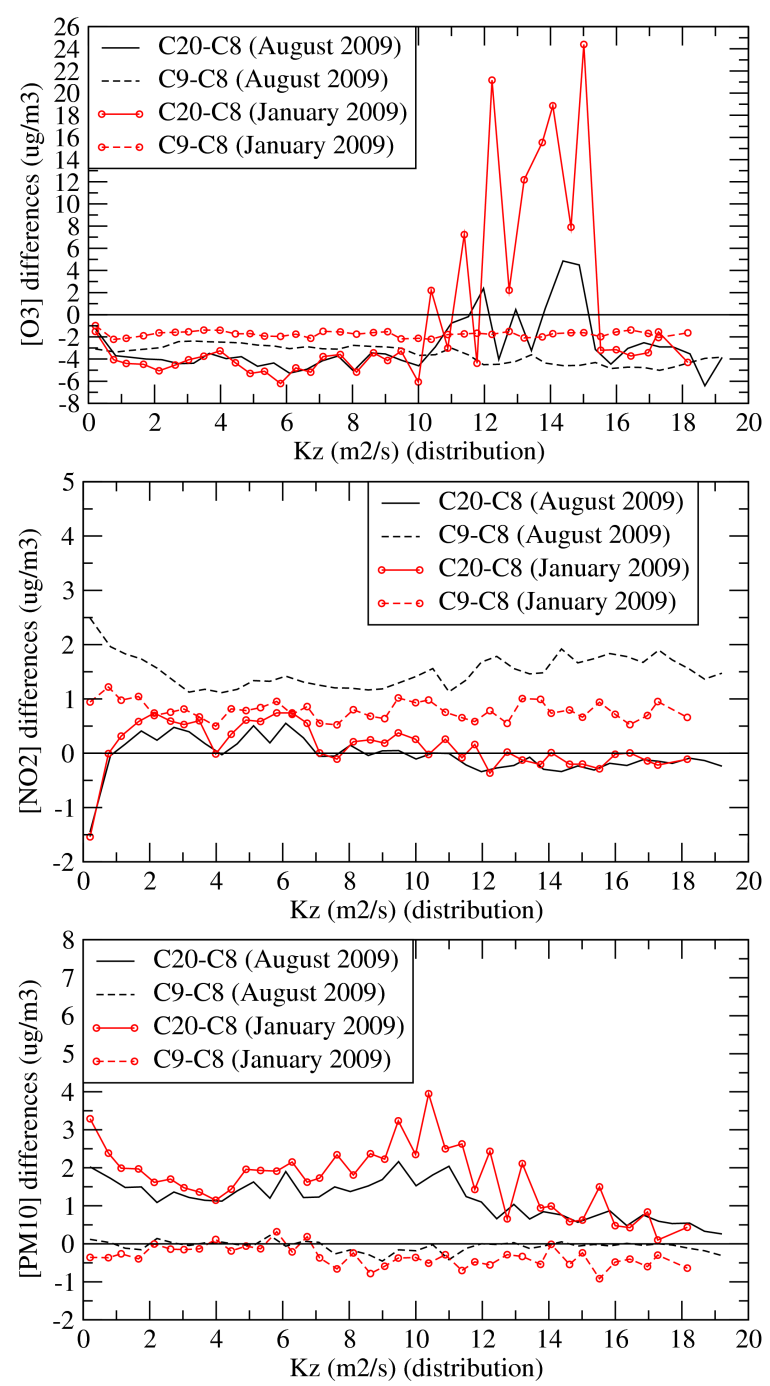

Figure 8: Distributions of concentrations differences as a function of the $K_{z}$ first model level values. The $K_{z}$ profiles being different between the model configurations, the C20 configuration was used here for the distributions calculations.

In order to quantify the impact of $\mathrm{K}_{z}$ on surface concentrations, the simulations are compared by ranking the concentrations differences, (C20-C8) and (C9-C8), as a function of the corresponding value of surface $\mathrm{K}_{z}$ (during August 2009). The surface $K_{z}$ values are discretised into regular bins of $1 \mathrm{~m}^{2} / \mathrm{s}$ step. For each $\mathrm{K}_{z}$ bin, the corresponding $(\mathrm{C} 20-\mathrm{C} 8)$ and $(\mathrm{C} 9-\mathrm{C} 8)$ hourly concentrations are averaged. The result gives an indication about the 
surface $\mathrm{K}_{z}$ value for which the most important concentrations differences are obtained. The results are displayed in Figure 8 , for $\mathrm{O}_{3}, \mathrm{NO}_{2}$ and $\mathrm{PM}_{10}$.

For ozone concentrations, the (C20-C8) and (C9-C8) differences for the two months are always negative in low $\mathrm{K}_{z}$ conditions. The differences do not exceed $-5 \mu \mathrm{g} / \mathrm{m}^{3}$. This means that in case of low mixing, adding a point near the surface or increasing the vertical resolution tends to have lower surface ozone concentrations. For higher $\mathrm{K}_{z}$ values, between 10 and $16 \mathrm{~m}^{2} / \mathrm{s}$, the differences turn positive and larger (up to $25 \mu \mathrm{g} / \mathrm{m}^{3}$ for the (C20-C8) and during January 2009. In the case of ozone, when the vertical diffusivity is high, during convective conditions, there is a competition between an enhanced titration close to the surface and an import of ozone coming from the upper layers. The large variability observed for ozone is not diagnosed for $\mathrm{NO}_{2}$ and $\mathrm{PM}_{10}$. The distributions are relatively flat and tend to show that the differences between the model configurations are not really sensitive to the mixing values near the surface.

For $\mathrm{NO}_{2}$, the values of differences are mainly positive, on average between 0 and $+2 \mu \mathrm{g} / \mathrm{m}^{3}$, showing that $\mathrm{C} 9$ and $\mathrm{C} 20$ tends to increase $\mathrm{NO}_{2}$ concentrations compared to the reference run $\mathrm{C} 8$. Negative values are only observed for very low mixing $\left(\mathrm{K}_{z}<1 \mathrm{~m}^{2} / \mathrm{s}\right)$ and for the C20 configuration. In this case, the refined vertical meshes gives lower $\mathrm{NO}_{2}$, but with moderate differences (with a maximum of $\left.-1.5 \mu \mathrm{g} / \mathrm{m}^{3}\right)$.

For $\mathrm{PM}_{10}$, the differences are always close to zero between C8 and C9. For this primary/secondary pollutant, whatever the $K_{z}$ value, i.e the stability conditions, there is a competition effect between chemistry and dynamics, that explains this feature. The chemistry leads to negative differences (as for ozone) and the dynamics to negative differences (as for $\mathrm{NO}_{2}$ ). The differences are higher between $\mathrm{C} 8$ and $\mathrm{C} 20$, with values up to $+3 \mu \mathrm{g} / \mathrm{m}^{3}$, showing that an increase of the vertical resolution will increase surface $\mathrm{PM}_{10}$ concentrations.

\section{Model to data comparison}

In the previous sections, the impact of a change in the vertical resolution was discussed by comparing various model configurations. Here we evaluate whether these changes give better modelled results when compared to measurements. These comparisons are performed thanks to the measurements issued from the local air quality network operating over the Paris area (AIRPARIF). Hourly measurements are used to evaluate the day to day variability and the change of diurnal cycles in the various model configurations.

\subsection{Surface time series}

Many previous studies have been carried out regarding the comparison of modelled surface concentrations with CHIMERE in the Paris area: the ESQUIF experiment
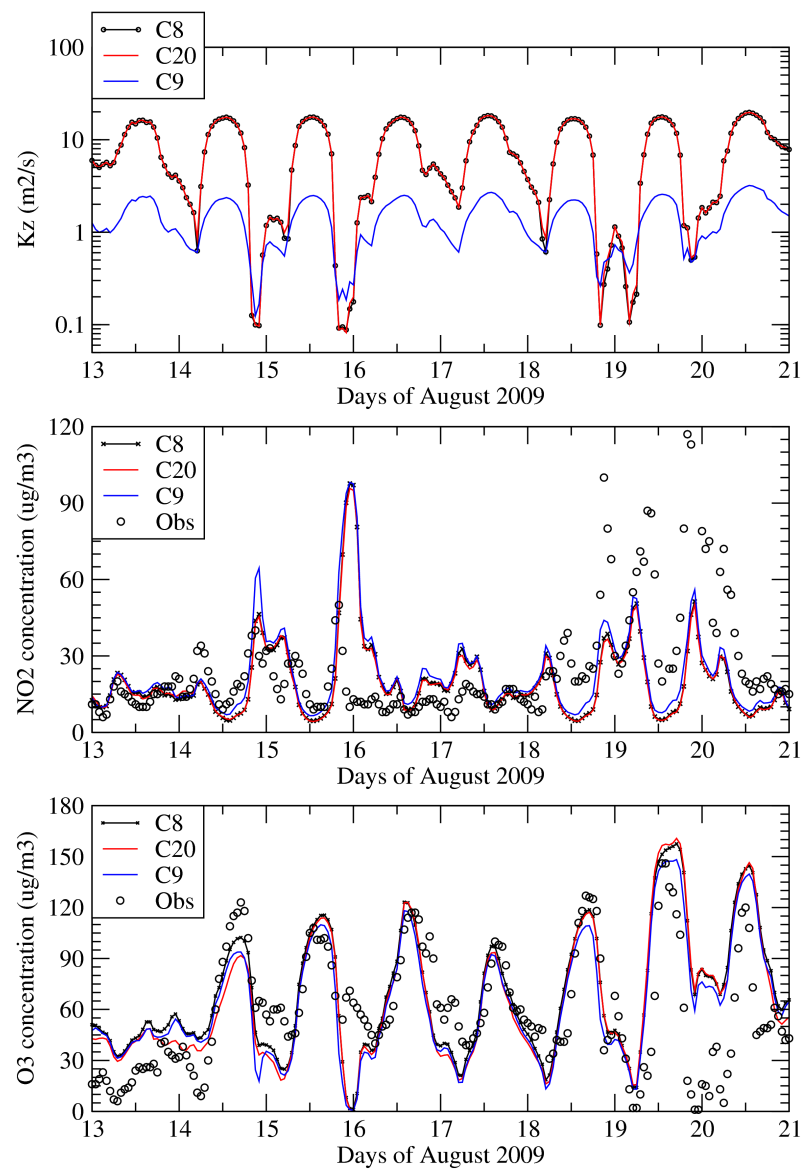

Figure 9: Example of times series of vertical turbulent diffusivity, ozone, $\mathrm{O}_{3}$, and nitrogen dioxide, $\mathrm{NO}_{2}$, at the first vertical level and during August 2009. Measurements and modelled concentrations represent the Paris center.

Menut et al. (2000), through the routine validation of the PREVAIR forecast system Rouil et al. (2009) or the sensitivity study of the horizontal resolution Valari and Menut (2008). It was shown that CHIMERE can accurately simulate and forecast ozone and $\mathrm{NO}_{2}$ concentrations. Since the goal of this paper is not to discuss again the model validation but to evaluate its sensitivity to the vertical resolution, this section does not contain a full quantitative performance analysis but more a qualitative discussion of a change in the horizontal resolution and $\mathrm{K}_{z}$ values on modelled pollutant concentrations.

Figure 9 displays time series at the first vertical model level of the turbulent diffusivity coefficient, $\mathrm{K}_{z}$, ozone and nitrogen dioxides concentrations. In order to focus on diurnal cycle changes, time series are restricted to the time period between the 13 and 21 August 2009, representative of a large day to day variability. The comparisons are done between the Paris grid cell for the model and the AIRPARIF network measurements, for the $\mathrm{NO}_{2}$ et $\mathrm{O}_{3}$ measurements data.

Figure 9 (top) shows the time series of $\mathrm{K}_{z}$ for the three configurations, C8, C20 and C9 and with a log scale along 
the $\mathrm{y}$ axe in order to have a focus on low values. Having the same first vertical level, the values for C8 and C20 are exactly the same: the diurnal variability ranges from 0.1 to $2 \mathrm{~m}^{2} / \mathrm{s}$ during the night (stable conditions) to $15-20 \mathrm{~m}^{2} / \mathrm{s}$ during the afternoon (fully convective conditions). For C9, the same kind of diurnal variability is observed but with lower values, between 0.1 and $4 \mathrm{~m}^{2} / \mathrm{s}$. For all configurations, very low $\mathrm{K}_{z}$ values are diagnosed for the nights of 14-15, 15-16 and 19-20 August 2009. The minimum $\mathrm{K}_{z}$ of $0.1 \mathrm{~m}^{2} / \mathrm{s}$ is reached for C8 and C20, but not for C9 (with higher values, $0.2 \mathrm{~m}^{2} / \mathrm{s}$ for the same time).

The comparison between modelled and measured $\mathrm{NO}_{2}$ concentrations ( Figure 9 (middle)) shows that the period is well modelled except (i) for the night of 15-16 August when the model overestimates the concentrations and, the period from 19 to 20 August, when the model underestimates the concentrations. In general, the most important $\mathrm{NO}_{2}$ surface concentrations are modelled during the night and the morning when the $K_{z}$ are the lowest. But, the fact that some $K_{z}$ were very low in the model has no a systematic impact on surface concentrations: for the night of 15-16 August, the $\mathrm{NO}_{2}$ overestimation can be attributed to the very low corresponding $K_{z}$ values. This is not the case for the night of 19-20 August when the model underestimates the $\mathrm{NO}_{2}$ while $\mathrm{K}_{z}$ values are also very low.

For ozone ( Figure 9 (bottom)), the day to day variability is well captured by the model, and the major daily peaks are well captured. The main differences between the three configurations occur during the night, when the $\mathrm{K}_{z}$ differ. This is the case of the 15-16 August night, when the modelled ozone concentrations tends to zero while the observations are about $50 \mu \mathrm{g} / \mathrm{m}^{3}$. This is a direct impact of the low $\mathrm{K}_{z}$ values, producing a low mixing and thus overestimating $\mathrm{NO}_{2}$ concentrations and $\mathrm{O}_{3}$ titration. For night of 19-20 August, the underestimation of $\mathrm{NO}_{2}$ concentration leads to non-zero ozone concentrations while the observations are close to zero.

The analysis of surface concentrations time series shows that the main impact of the vertical resolution occurs at night, when $\mathrm{K}_{z}$ is very low and similar to the minimum value imposed in the model. These low values may induce very large overestimation of primary species such as $\mathrm{NO}_{2}$, and in turn an underestimation of nocturnal ozone.

Even if the change of the vertical resolution involves differences in modelled surface concentrations, these differences remain low compared to the differences between model and measurements. It appears obvious that the change in vertical resolution or the height of the first vertical level is not the most sensitive parameter in the modelling system even if refining the vertical mesh has a significan beneficial impact.

\subsection{Diurnal cycles and comparisons to observations}

In order to have an overview of the main differences, diurnal cycles are calculated for the whole months of January and August 2009. Cycles are calculated for ozone,
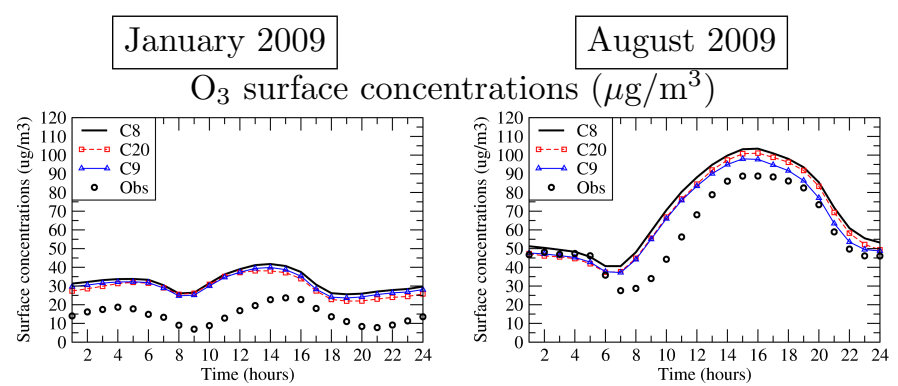

$\mathrm{NO}_{2}$ surface concentrations $\left(\mu \mathrm{g} / \mathrm{m}^{3}\right)$
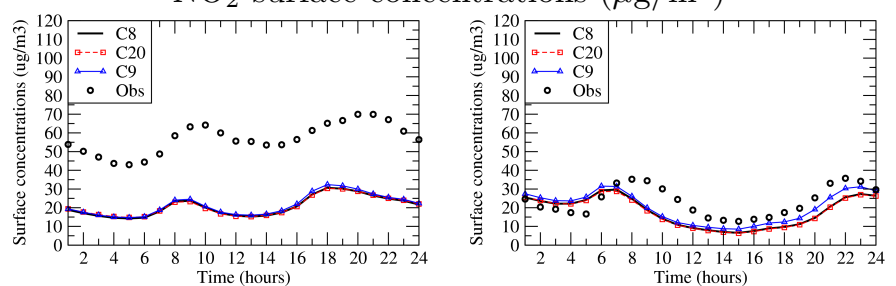

$\mathrm{PM}_{10}$ surface concentrations $\left(\mu \mathrm{g} / \mathrm{m}^{3}\right)$
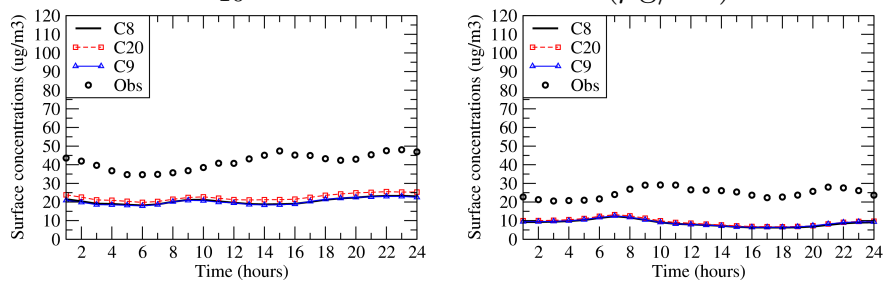

Figure 10: Diurnal cycles for surface concentrations of ozone, $\mathrm{NO}_{2}$ and $P M_{10}$, January and August 2009 for Paris.

$\mathrm{NO}_{2}$ and $\mathrm{PM}_{10}$ for the three model configurations and for the corresponding surface measurements in the center of Paris. The same cycles were also calculated for other locations in the Paris area and similar behaviors were observed: the discussion is thus focusing on the Paris station.

The model tends to overestimate ozone concentrations, and underestimate $\mathrm{NO}_{2}$ and $\mathrm{PM}_{10}$ concentrations. The correlation is good, and the main differences are related to a near-constant bias during the whole day. The most important differences occur during winter, when the boundary layer is less convective and with a lower boundary layer height. The C9 model configuration gives modelled concentrations closer to the measurements than C8 and C20. But the differences between the different model configurations are not so large compared to the differences with the measurements. The most important impact of C9 is for ozone and during summer, reducing the overestimation of the peaks during the afternoon.

\section{Discussion and conclusion}

This study is dedicated to an evaluation of the impact of different vertical resolutions in modelling near surface concentrations. The 'reference' vertical mesh was defined as the mesh used for the PREVAIR forecast platform using CHIMERE: 8 vertical levels, called C8, ranging from 995 $\mathrm{hPa}(\approx 40 \mathrm{~m}$ above ground level $)$ to $500 \mathrm{hPa}(\approx 5000 \mathrm{~m}$ 
agl). Two other meshes were defined: one with the same pressure boundaries (995 to $500 \mathrm{hPa}$ ), but with 20 vertical levels (called C20); and one with exactly the same 8 levels, but with an additional level close to the surface, at $999 \mathrm{hPa}$ ( $\approx 8 \mathrm{~m}$ above ground level), called C9.

The quantification of the impact of these different meshes was done by comparing directly the simulations amongst themselves as well as against surface measurements. The domain is the Paris area and the periods studied were chosen to be different in terms of pollution events: the whole month of January 2009 for $\mathrm{NO}_{2}$ and $\mathrm{PM}_{10}$ pollution, and the whole month of August 2009 for photochemical pollution with ozone, $\mathrm{O}_{3}$.

Based on monthly averaged maps, it was shown that the differences between $\mathrm{C} 8$ and $\mathrm{C} 20$ never exceed $3 \mu \mathrm{g} / \mathrm{m}^{3}$ during winter and summer and over the whole area. The patterns of differences are mostly related to the main surface emissions sources, here the Paris city, and are slightly spatially shifted of a few kilometers, showing the main wind regimes over the region and the transport of pollutants. In average, a refined mesh $(\mathrm{C} 20)$ tends to give more $\mathrm{NO}_{2}$ and $\mathrm{PM}_{10}$ and less ozone than C8. Vertically, C20 is able to capture finer structures, both for gases $\left(\mathrm{O}_{3}\right)$ and particles $\left(\mathrm{PM}_{10}\right)$. These vertical structures have no significant impact on the surface concentrations. The comparison of averaged vertical profiles of vertical diffusivity $\mathrm{K}_{z}$ and pollutants showed that the differences between C8, C20 and C9 are low.

Adding a new point near the surface (C9 simulation) leads to concentrations that are more representative of the height of surface stations measurements. But the differences between C8 and C9 are moderate and cannot fully explain the differences between the model and measurements.

Distributions are calculated to discriminate the concentrations differences as a function of $\mathrm{K}_{z}$ values. Globally, there is no clear signal and the differences seems to be relatively independent of the diffusivity values, except for $\mathrm{NO}_{2}$ and the lowest $\mathrm{K}_{z}$ values (between 0.1 and $1 \mathrm{~m}^{2} / \mathrm{s}$ ) and for ozone in case of strong surface diffusivity (i.e $K_{z}$ $\left.\approx 15 \mathrm{~m}^{2} / \mathrm{s}\right)$.

Comparisons with surface measurements were performed as time series and diurnal cycles. The main differences between the model and measurements were observed at night, when the vertical diffusivity shows very low values. But this feature is not systematic and, for some cases, low $\mathrm{K}_{z}$ are not the reason for large model to observations differences. The diurnal cycles show an overestimation of surface ozone concentrations and an underestimation of $\mathrm{NO}_{2}$ and $\mathrm{PM}_{10}$. But for the three vertical meshes, none is able to sufficiently unbias the model.

Finally, it was shown that different vertical meshes may change of a few $\mu \mathrm{g} / \mathrm{m}^{3}$ the modelled surface concentrations over a large urbanised area such as Paris. This variability is much smaller than the differences between measurements and predicted values. Changing the vertical mesh may be more realistic in specific cases: high concentrated ozone layers in the boundary layer, nocturnal concentrations of gas and particles in case of very stable nocturnal boundary layers.

The C8 configuration correspond to the one used in the PREVAIR operational system. We thus showed that the differences when using a refined mesh $(\mathrm{C} 20)$ or a mesh with a point closest to the surface (C9) are low. This means that results of the $\mathrm{C} 8$ operational forecast are not due primarily to the vertical mesh definition.

However, the interest to add a point closest to the surface (C9) has been shown and this correspond to modify the 'urban increment' roughly defined as the difference between the city and background concentrations. This expected change is due to the conbined effects of (i) higher deposition rates in remote areas (over vegetative covers) and (ii) higher (or lower for ozone) concentrations over emission areas. The background values seems to be more affected by a change of the whole vertical resolution (simulation C20). This study was conducted over an highly urbanised area, known to be poorly represented in terms of sub-grid scale dynamical processes. While the first layer of $\mathrm{C} 8$ and $\mathrm{C} 20(40 \mathrm{~m})$ is more related to the buildings top heights, C9 $(8 \mathrm{~m})$ is representative of the urban canopy layer and this should be expressed in the vertical mixing representation. Actually, this is not the case in the current CHIMERE version and has certainly to be improved in future model developments.

\section{Acknowledgments}

This study was partly funded by the french Ministry in charge of Environment. This work was done under the auspices of the European project EC4MACS (EU LIFE, www.ec4macs.eu).

\section{References}

Andersson, C., Bergstrm, R., Johansson, C., 2009. Population exposure and mortality due to regional background pm in europe long-term simulations of source region and shipping contributions. Atmospheric Environment 43 (22-23), 3614 - 3620.

Aristodemou, E., Bentham, T., Pain, C., Colvile, R., Robins, A., ApSimon, H., 2009. A comparison of mesh-adaptive LES with wind tunnel data for flow past buildings: Mean flows and velocity fluctuations. Atmospheric Environment 43 (39), 6238 - 6253.

Bessagnet, B., Menut, L., Aymoz, G., Chepfer, H., Vautard, R., 2008. Modelling dust emissions and transport within Europe: the Ukraine March 2007 event. Journal of Geophysical Research 113, D15202.

Bessagnet, B., Seigneur, C., Menut, L., 2010. Impact of dry deposition of semi-volatile organic compounds on secondary organic aerosols. Atmospheric Environment 44, 1781-1787.

Bicheron, P., et al., September 2008. Geolocation assessment of $300 \mathrm{~m}$ resolution MERIS GLOBCOVER ortho-rectified products. In: Proceedings of MERIS/AATSR Colloque. Frascati.

Byun, D., Dennis, R., 1995. Design artifacts in eulerian air quality models: Evaluation of the effects of layer thickness and vertical profile concentration on surface ozone concentrations. Atmospheric Environment 29 (1), 105-126. 
Chamecki, M.R. van Hout, C., Meneveau, C., Parlange, M., 2007. Concentration profiles of particles settling in the neutral and stratified atmospheric boundary layer. Boundary-Layer Meteorology 125 (1), 25-38.

Cheinet, S., Teixeira, J., 2003. A simple formulation for the eddydiffusivity parameterization of cloudtopped boundary layers. Geophys. Res. Lett. 30 (18).

Chen, F., Dudhia, J., 2001. Coupling an advanced landsurface/hydrology model with the penn state NCARMM5 modeling system. part i: Model implementation and sensitivity. Mon. Wea. Rev. 129, 569-585.

Cionco, R. M., Ellefsen, R., 1998. High resolution urban morphology data for urban wind flow modeling. Atmospheric Environment 32 (1), $7-17$.

Colette, A., Favez, O., Meleux, F., Chiappini, L., Haeffelin, M., Morille, Y., Malherbe, L., Papin, A., Bessagnet, B., Menut, L., Leoz, E., Rouil, L., 2011. Assessing in near real time the impact of the April 2010 Eyjafjallajokull ash plume on air quality. Atmospheric Environment 45, 1217-1221.

Davies, F., Middleton, D., Bozier, K., 2007. Urban air pollution modelling and measurements of boundary layer height. Atmospheric Environment 41 (19), 4040 - 4049.

Derognat, C., Beekmann, M., Baeumle, M., Martin, D., Schmidt, H., 2003. Effect of biogenic voc emissions on the tropospheric chemistry during elevated ozone periods in ile de france. J. Geophys. Res. 108.

Garmory, A., Kim, I., Britter, R., Mastorakos, E., 2009. Simulations of the dispersion of reactive pollutants in a street canyon, considering different chemical mechanisms and micromixing. Atmospheric Environment 43 (31), 4670 - 4680.

Guenther, A., Karl, T., Harley, P., Wiedinmyer, C., Palmer, P. Geron, C., 2006. Estimates of global terrestrial isoprene emissions using MEGAN (Model of Emissions of Gases and Aerosols from Nature). Atmos. Chem. Phys. 6, 31813210.

Hara, T., Castelli, S. T., Ohba, R., Tremback, C., 2009. Validation studies of turbulence closure schemes for high resolutions in mesoscale meteorological models - a case of gas dispersion at the local scale. Atmospheric Environment 43 (24), 3745 - 3753.

Hong, S. Y., Dudhia, J., Chen, S., 2004. A revised approach to ice microphysical processes for the bulk parameterization of clouds and precipitation. Mon. Weather Rev. 132, 103-120.

Hong, S. Y., Noh, Y., Dudhia, J., 2006. A new vertical diffusion package with an explicit treatment of entrainment processes. Mon. Weather Rev. 134, 2318-2341.

Honoré, C., Rouil, L., Vautard, R., Beekmann, M., Bessagnet, B. Dufour, A., Elichegaray, C., Flaud, J., Malherbe, L., Meleux, F., Menut, L., Martin, D., Peuch, A., Peuch, V., Poisson, N., 2008. Predictability of European air quality: The assessment of three years of operational forecasts and analyses by the PREV'AIR system. Journal of Geophysical Research 113, D04301.

Imhof, D., Weingartner, E., Vogt, U., Dreiseidler, A., Rosenbohm, E., Scheer, V., Vogt, R., Nielsen, O., Kurtenbach, R., Corsmeier, U., Kohler, M., Baltensperger, U., 2005. Vertical distribution of aerosol particles and nox close to a motorway. Atmospheric Environment 39 (31), $5710-5721$

Kain, J., 2004. The Kain-Fritsch convective parameterization: an update. J Appl Meteorol 43, 170-181.

Kim, Y., Fu, J. S., Miller, T. L., 2009. Improving ozone modeling in complex terrain at a fine grid resolution: Part I - examination of analysis nudging and all PBL schemes associated with LSMs in meteorological model. Atmospheric Environment In Press, Corrected Proof, -

Lee, H. W., Choi, H.-J., Lee, S.-H., Kim, Y.-K., Jung, W.-S., 2008. The impact of topography and urban building parameterization on the photochemical ozone concentration of seoul, korea. Atmospheric Environment 42 (18), 4232 - 4246.

Lin, J., McElroy, M., 2010. Impacts of boundary layer mixing on pollutant vertical profiles in the lower troposphere: Implications to satellite remote sensing. Atmospheric Environment, 1-14.

Louis, J., Tiedke, M., Geleyn, J., 1982. A short history of the PBL parametrization at ECMWF. In: ECMWF Workshop on Plane- tary Boundary Layer parametrization. Reading, pp. 59-80.

Menut, L., Bessagnet, B., 2010. Atmospheric composition forecasting in Europe. Annales Geophysicae 28, 61-74.

Menut, L., Goussebaile, A., Bessagnet, B., Khvorostiyanov, D., Ung, A., 2012a. Impact of realistic hourly emissions profiles on modelled air pollutants concentrations. Atmospheric Environment, 233244

Menut, L., Tripathi, O., Colette, A., Vautard, R., Flaounas, E., Bessagnet, B., 2012b. Evaluation of regional climate simulations for air quality modelling purposes. Climate Dynamics in press.

Menut, L., Vautard, R., Flamant, C., Abonnel, C., Beekmann, M., Chazette, P., Flamant, P., Gombert, D., Guédalia, D., Lefebvre, M., Lossec, B., D., M., Mégie, G., Perros, P., Sicard, M., Toupance, G., 2000. Measurements and modelling of atmospheric pollution over the Paris area: an overview of the ESQUIF Project. Annales Geophysicae 18 (11), 1467-1481.

Mlawer, E. J., Taubman, S., Brown, P., Iacono, M., Clough, S., 1997. Radiative transfer for inhomogeneous atmosphere: RRTM, a validated correlated k-model for the longwave. J. Geophys. Res. $102,16663-16682$

Murena, F., Favale, G., Vardoulakis, S., Solazzo, E., 2009. Modelling dispersion of traffic pollution in a deep street canyon: Application of cfd and operational models. Atmospheric Environment 43 (14), $2303-2311$.

Nenes, A., Pilinis, C., Pandis, S., 1998. ISORROPIA: A new thermodynamic model for inorganic multicomponent atmospheric aerosols. Aquatic Geochem. 4, 123-152.

Pierce, T., Hogrefe, C., Rao, S. T., Porter, P. S., Ku, J.-Y., 2010. Dynamic evaluation of a regional air quality model: Assessing the emissions-induced weekly ozone cycle. Atmospheric Environment 44 (29), $3583-3596$.

Priestley, C., 1949. Heat transport and zonal stress between latitudes. Quaterly Journal of the Royal Meteorology 75, 28-40.

Righi, S., Lucialli, P., Pollini, E., 2009. Statistical and diagnostic evaluation of the adms-urban model compared with an urban air quality monitoring network. Atmospheric Environment 43 (25), $3850-3857$.

Rouil, L., Honore, C., Vautard, R., Beekmann, M., Bessagnet, B., Malherbe, L., Meleux, F., Dufour, A., Elichegaray, C., Flaud, J., Menut, L., Martin, D., Peuch, A., Peuch, V., Poisson, N., 2009. PREV'AIR : an operational forecasting and mapping system for air quality in Europe. BAMS 90, 73-83.

Santos, J. M., Jr., N. C. R., Goulart, E. V., Mavroidis, I., 2009. Numerical simulation of flow and dispersion around an isolated cubical building: The effect of the atmospheric stratification. Atmospheric Environment 43 (34), 5484 - 5492.

Schaap, M., Vautard, R., Bergstrom, R., van Loon, M., Bessagnet, B., Brandt, J., Christensen, H., Cuvelier, K., Foltescu, V., Graff, A., E., J. J., Kerschbaumer, A., Krol, M., Langner, J., Roberts, P., Rouil, L., Stern, R., Tarrason, L., Thunis, P., Vignati, E., White, L., Wind, P., Builtjes, P. H. J., 2007. Evaluation of longterm aerosol simulations from seven air quality models and their ensemble in the eurodelta study. Atmospheric Environment, submitted.

Schmidt, H., Derognat, C., Vautard, R., Beekmann, M., 2001. A comparison of simulated and observed ozone mixing ratios for the summer of 1998 in western Europe. Atm. Env. 35, 6277-6297.

Troen, I., Mahrt, L., 1986. A simple model of the atmospheric boundary layer: Sensitivity to surface evaporation. Bound.-Layer Meteorol. $37,129-148$.

Valari, M., Chatignoux, E., Menut, L., 2011. Using a chemistry transport model to account for the spatial variability of exposureconcentrations in epidemiologic air pollution studies. Journal of the Air and Waste Management Association 61, 164-179.

Valari, M., Menut, L., 2008. Does increase in air quality models resolution bring surface ozone concentrations closer to reality? Journal of Atmospheric and Oceanic Technology.

van Loon, M., Vautard, R., Schaap, M., Bergström, R., Bessagnet, B., Brandt, J., Builtjes, P., Christensen, J., Cuvelier, C., Graff, A., Jonson, J., Krol, M., Langner, J., Roberts, P., Rouïl, L., Stern, R., Tarrasón, L., Thunis, P., Vignati, E., White, L., 
Wind, P., 2007. Evaluation of long-term ozone simulations from seven regional air quality models and their ensemble. Atmospheric Environment 41 (10), 2083 - 2097.

Vautard, R., B.Bessagnet, M.Chin, Menut, L., 2005. On the contribution of natural Aeolian sources to particulate matter concentrations in Europe: testing hypotheses with a modelling approach. Atmospheric Environment 39, 3291-3303.

Vautard, R., Maidi, M., Menut, L., Beekmann, M., Colette, A., 2007. Boundary layer photochemistry simulated with a two-stream convection scheme. Atmospheric Environment 41, 8275-8287.

Xiao, J., Taylor, P., 2002. On equilibrium profiles of suspended particles. Boundary-Layer Meteorology 105, 471-482. 
(C20-C8) $\mathrm{NO}_{2}$ - January 2009

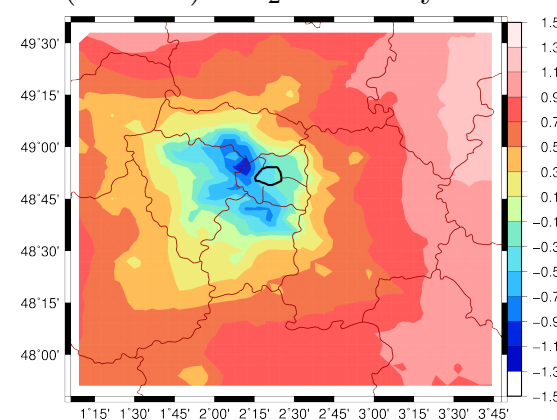

(C9-C8) $\mathrm{NO}_{2}$ - January 2009

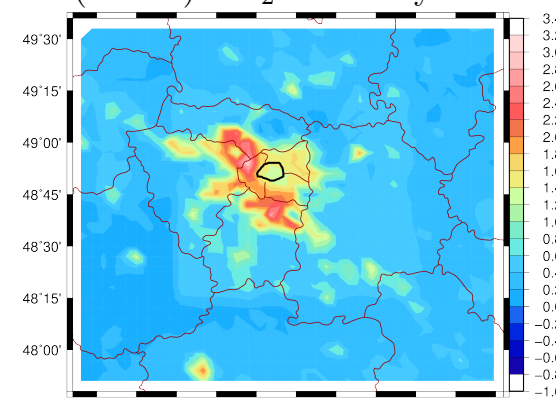

(C20-C8) $\mathrm{NO}_{2}$ - August 2009

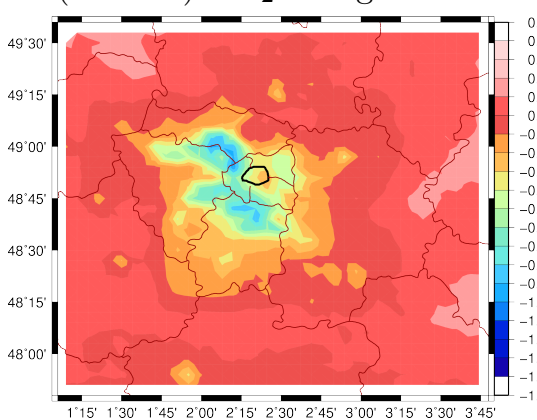

(C9-C8) $\mathrm{NO}_{2}$ - August 2009

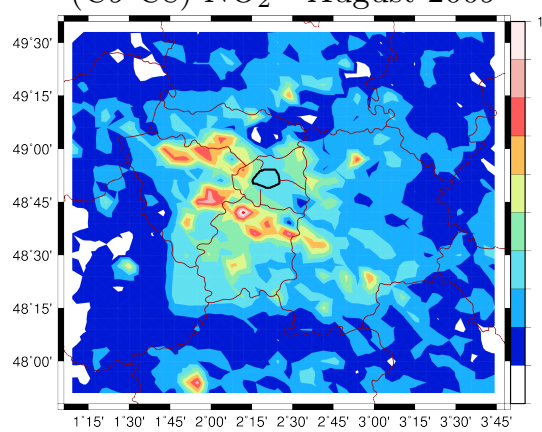

(C20-C8) PM $_{10}$ - January 2009
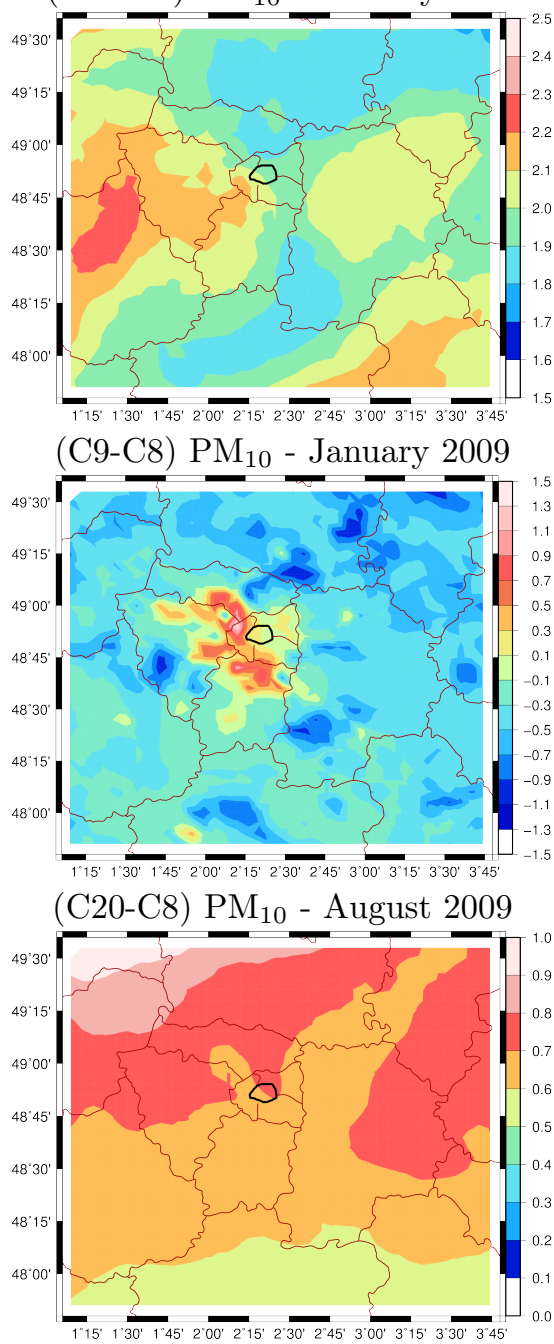

(C9-C8) $\mathrm{PM}_{10}$ - August 2009

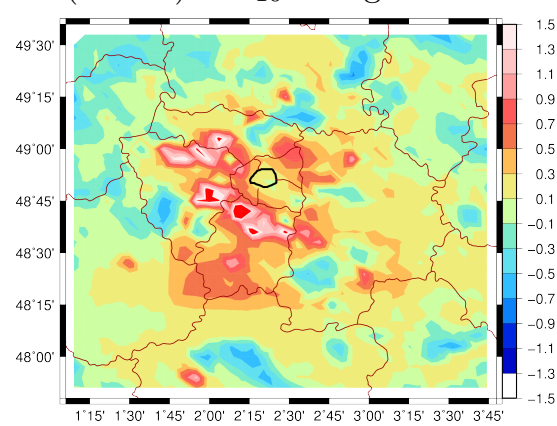

(C20-C8) $\mathrm{O}_{3}$ - January 2009

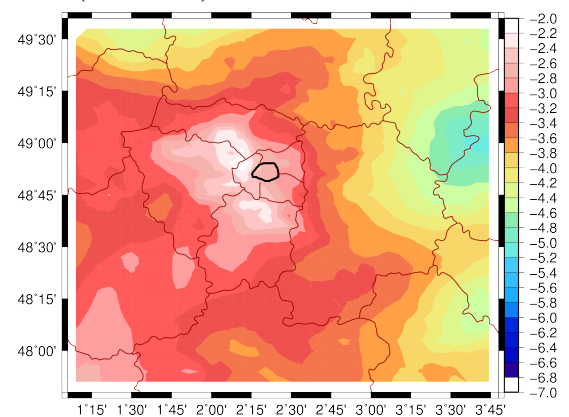

(C9-C8) $\mathrm{O}_{3}$ - January 2009

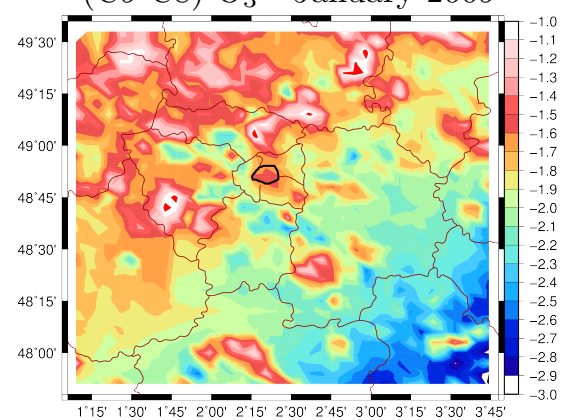

(C20-C8) $\mathrm{O}_{3}$ - August 2009

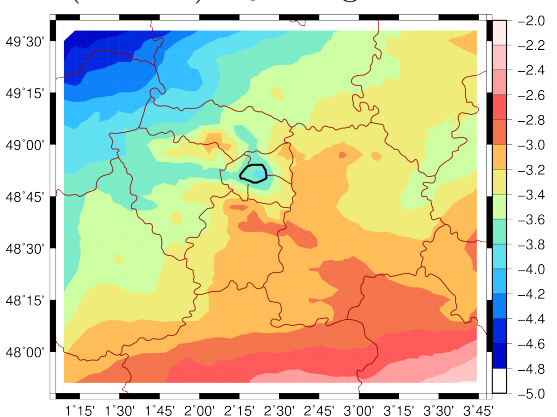

(C9-C8) $\mathrm{O}_{3}$ - August 2009

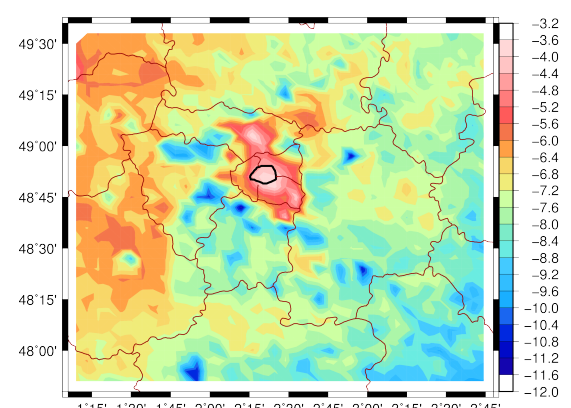

Figure 5: Maps of (C20-C8) and (C9-C8) surface averaged concentrations differences for $\mathrm{O}_{3}, \mathrm{NO}_{2}$ and PM10 and for January and August 2009. All pollutants concentrations are expressed in $\mu \mathrm{g} / \mathrm{m}^{3}$. 

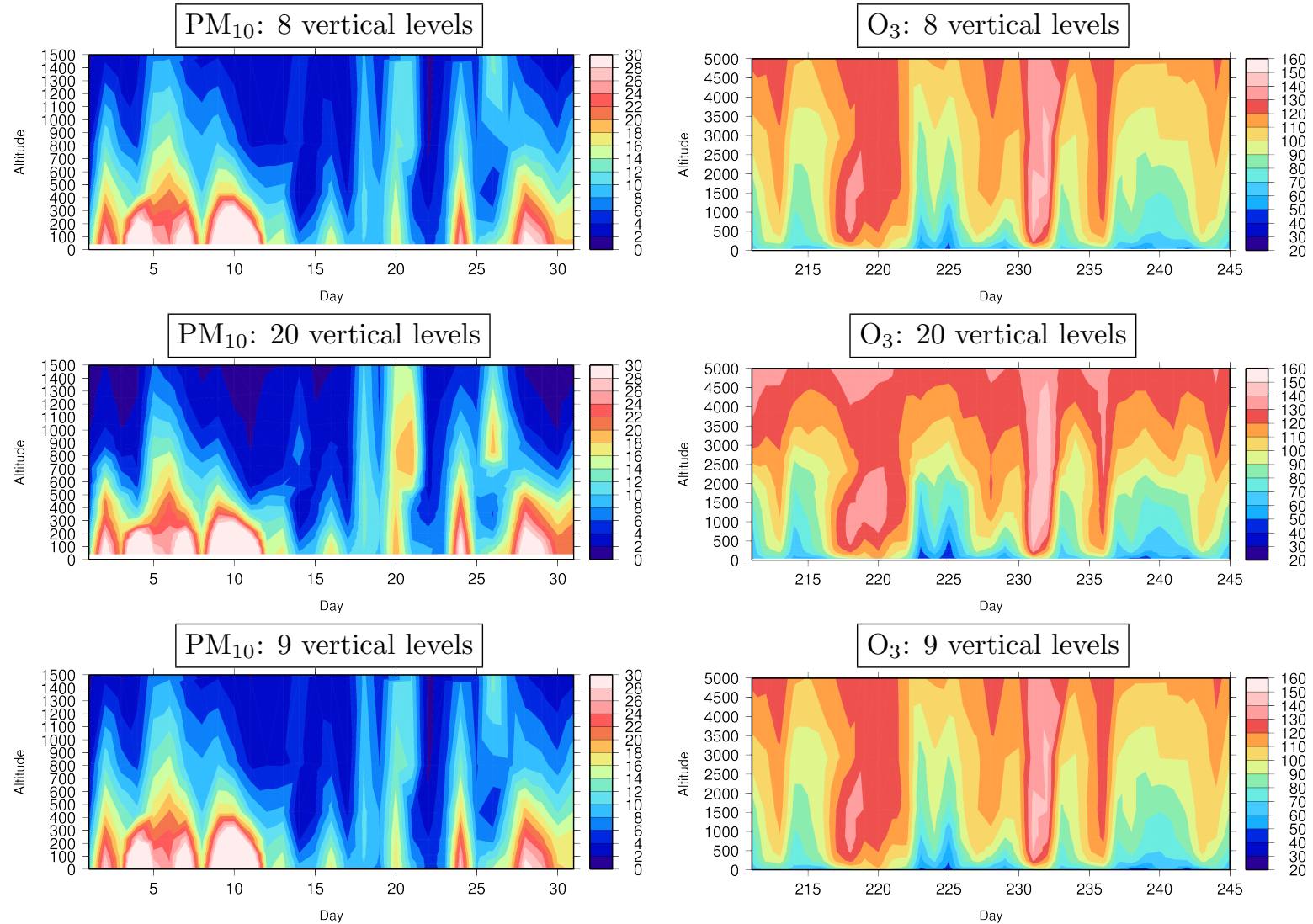

Figure 6: Vertical cross section of [left] $P M_{10}$ concentrations $\left(\mu \mathrm{g} / \mathrm{m}^{3}\right)$ for January 2009 and [right] $\mathrm{O}_{3}$ concentrations ( $\left.\mu \mathrm{g} / \mathrm{m}^{3}\right)$ for August 2009. 

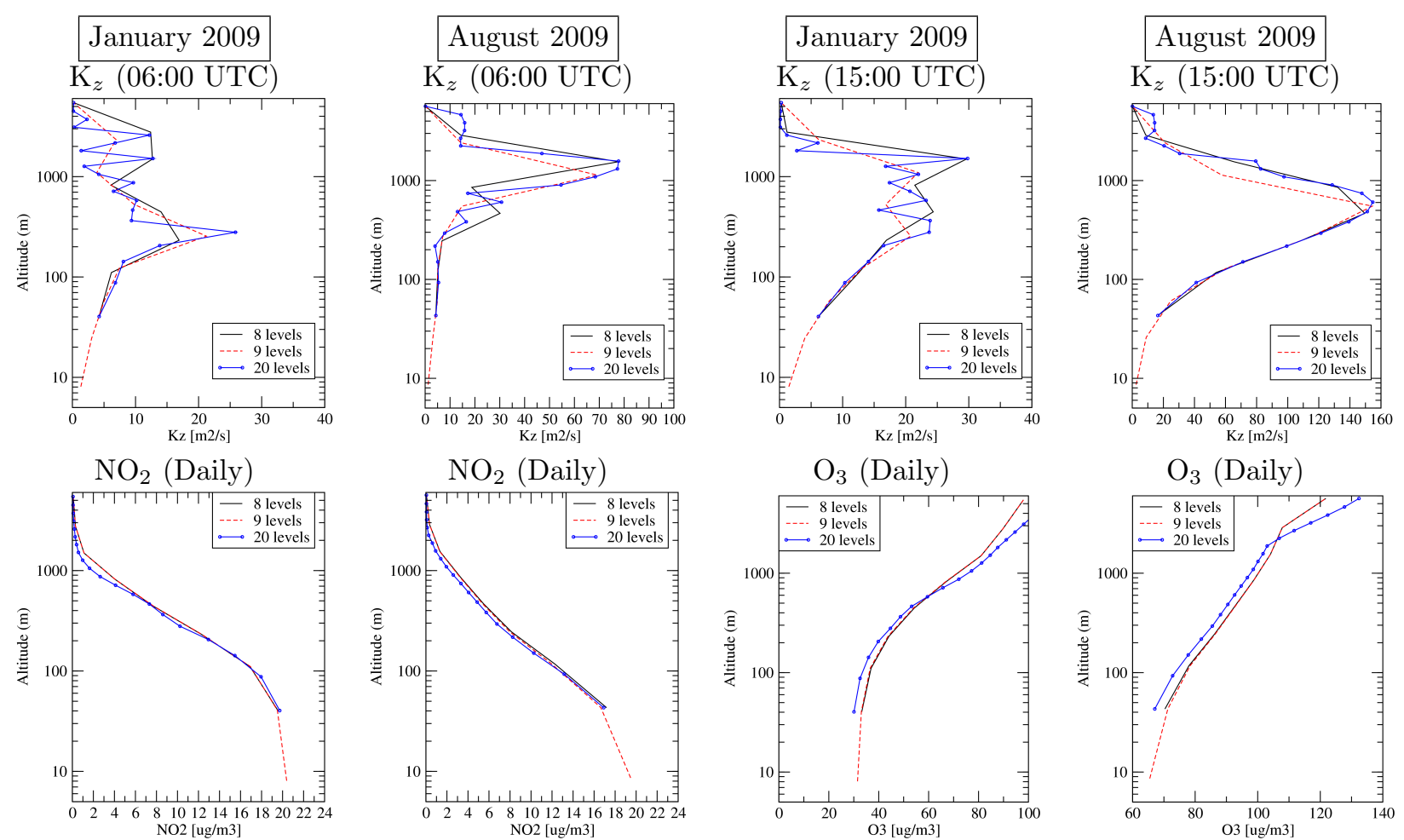

Figure 7: Vertical profiles of $\mathrm{Kz}, \mathrm{NO}_{2}$ and $\mathrm{O}_{3}$, for January and August 2009 over Paris. The profiles are averaged for each month of January and August 2009 using only 06:00 and 15:00 UTC for $\mathrm{K}_{z}$, and all day hours for $\mathrm{NO}_{2}$ and $\mathrm{O}_{3}$. 